\title{
Numerical modeling of the hydraulic impact of riparian vegetation
}

\author{
Krzysztof Wolski ${ }^{1, *}$, Tomasz Tymiński ${ }^{1}$, and Grzegorz Chrobak $^{2}$ \\ ${ }^{1}$ Wroclaw University of Environmental and Life Sciences, The Faculty of Environmental Engineering \\ and Geodesy, Institute of Environmental Engineering, C. K. Norwida 25, 50-375 Wroclaw, Poland \\ ${ }^{2}$ Wroclaw University of Environmental and Life Sciences, The Faculty of Environmental Engineering \\ and Geodesy, Institute of Environmental Protection and Development, C. K. Norwida 25, 50-375 \\ Wroclaw, Poland
}

\begin{abstract}
This paper presents results of numerical modelling of riverbed segment with riparian vegetation performed with use of CCHE2 software. Vegetation zones are places where dynamic of water flow increases. Therefore, there is a need of careful examination of hydraulic impact structure of such zones. Accurate research is necessary and should be performed with use of physical or numerical models, two or three dimensional. Paper presents distribution of velocity and area of water surface for two variants of vegetation deposition acquired in CCHE2D software and modelled for riverbed with distinctive riparian vegetation. Results point to significant (30-40\%) increase of maximal velocities in riverbed with riparian vegetation, while directly near the vegetation there were zones with very low velocities. Local damming occurs before vegetal zone. Maximal shear stress in zones with increased velocity is significantly augmented compared to conditions with no vegetation, which can cause more intensive erosion in those zones
\end{abstract}

\section{Introduction}

Vegetation, through the additional flow resistance that it generates, influences water depth, mean flow velocities and turbulence, sediment dynamics, water quality and habitat diversity [1]. Historically, aquatic vegetation in streams was considered only as a source of flow resistance. Thus entire vegetation was frequently removed to enhance flow conveyance and reduce flooding [2]. Meanwhile, research in recent years underlines the positive role that vegetation plays in the ecosystem of the river. Plants are called „,ecological engineers”. Meire lists numerous reasons, such as: decreasing erosion, reducing turbidity, improving water quality and providing habitat for many species [3]. Nepf and Ghisalberti add yet: creation of regions with diminished bed stress that promote sedimentation and retention of particles and increasing habitat diversity, and thus species diversity, by introducing spatial heterogeneity to the velocity field [4]. This topic is currently very popular due to the trend towards a friendly nature of river regulation and restoration processes. However, it is stressed, that studies need collaboration between disciplines to design sustainable systems.

\footnotetext{
*Corresponding author: krzysztof.wolski@upwr.edu.pl
} 
The characterization of natural vegetation for hydraulic analyses is complicated because plants (emergent, submergent, floating-leaf, free-floating and mixed type), grass, shrubs and trees exhibit a complex structure and are comprised of heterogeneous plant parts [5]. Furthermore, spatial distribution of plants in reach is very complicated and difficult to describe, especially, since plants location and size is a function of time and flow. This is caused by scale impact, at which vegetation resistance operates are proposed. Resistance is shown to be a function of the size of the plants, their structural properties, location in the channel, and the local flow conditions [6].

Flow resistance can be considered in spatial scales from individual blades through canopies or vegetation patches, to the channel reach. At the blade scale, the boundary layer formed on the plant surface plays a main role. Resistance can be caused also through the interaction with individual leaves and the reconfiguration of flexible blades. Alternatively, resistance can be considered to operate at the scale of the plant stand, where many stems and leaves act together to form a blockage to the flow, because each stem/leaf will cause variations in flow velocity in the vicinity of each stem $[1,2]$.

At the canopy scale, there are two flow regimes. For sparse canopies, the flow resembles a rough boundary layer. For dense canopies, the flow resembles a mixing layer. Research in canopy scale (otherwise called patch-scale) was conducted mostly on the idealized physical parameters of plants. However, flow adjustment around vegetation patches controls the magnitude of form that drag exerted on the flow. This interaction makes research more difficult. $[2,7]$.

At the reach scale, flow resistance is more closely connected to the patch-scale vegetation distribution, described by the blockage factor, rather than by the geometry of individual plants. Previous studies have shown that it is usual for the stand scale of resistance to dominate over the leaf scale for such species [2].

In relation to abovementioned complexities there are many various approaches used concerning the geometrical characteristics of vegetation paying special attention to its hydraulic impact. They were well discussed in numerous reviews [e.g. 8-10].

Difficulties related to simulation of various physical processes with real hydraulic models led to the development of mathematical modelling [11]. Depending on the number of coordinates required for water flow description, the computer systems used for hydrodynamic phenomena modelling are classified as follows: one-dimensional (1D), twodimensional (2D) and three-dimensional (3D) [12].

1D models (e.g. HEC-RAS, MIKE 11, SMS, CCHE1D, FLUVIAL) simulate flow between defined subsequent cross-sections. In those models the major problem is to adequately represent vegetation. It is defined only by the roughness coefficient in given crosssection. 1D models are generally simple, simulation interval is short in comparison to models, and there is no need to supply it with large amount of input data. However, typical obtained results are not sufficient enough to conduct detailed conditions analysis in more complicated systems, such as vegetal zones.

2D models (e g. HEC-RAS, MIKE 21, CCHE2D) are based on spatially distributed parameters of riverbed geometry and on roughness coefficients. These model require much more input data, simulation interval is multiply longer than in 1D models, which is important during modelling of large areas. However the obtained results provide much better analysis of water flow through vegetation zones. It is also possible to interpret results paying special attention to accurate spatial location of water table and to the velocity distribution in two directions: $\mathrm{x}$ and $\mathrm{y}$.

3D models (e g. MIKE 3, CCHE3D, DELFT3D, FLOW-3D) are able, in relation to 2D models, to show vertical movement of water. In case of modelling of individual plants it might be of great importance. The complexity of 3D hydraulic models allows all properties to be accounted for, but how efficient is capturing every single detail or using a $3 \mathrm{D}$ model in 
practice remains questionable. This is particularly due to the higher computational effort and data requirement needed, cost and time wise, which makes it less appealing to the industry. There is room for improvement in producing a practical model to derive vegetative roughness at a more accurate level for hydraulic modelling [10-12]. In relation to what was said above, in this paper numerical modelling of the hydraulic impact of riparian vegetation was performed with use of 2D software - CCHE2D.

\section{Study area}

The research was conducted for the segment of riverbed with two types of riparian vegetation distribution. The scheme of vegetation distribution is shown of Fig.1. A simplified scheme of riverbed with vegetation was chosen in order to verify acquired results on laboratory physical model. However, it was outside of scope of this paper. The area of study is a straight cuboidal riverbed with decrease. The riverbed is 0.5 meter wide and 5 meters long, from which in the model a segment 1.5 meters long is analyzed. Vegetation in the first variant (variant A) is in a form of $0.5 \mathrm{~m}$ long vegetation belt on the left bank with length of $0.2 \mathrm{~m}$. In the second variant (variant $B$ ) vegetation is distributed on both banks so that its combined width in riverbed equals $0.2 \mathrm{~m}$. Computations were also performed for variant with no riparian vegetation (variant 0 ). The depth of riverbed equals $0.5 \mathrm{~m}$. The height of vegetation is $0.35 \mathrm{~m}$. The vegetation is expected to act as rigid element and averaged diameter of particular plants equals ca. $0.02 \mathrm{~m}$ at the surface, and it becomes tighter in case of higher plants, forming $0.35 \mathrm{~m}$ long cone. It is assumed that water never reaches the height of vegetation, so the simulated vegetation can be described as truncated cones. Such approach to modelled vegetation was accepted before in numerous research $[8,13-16]$.
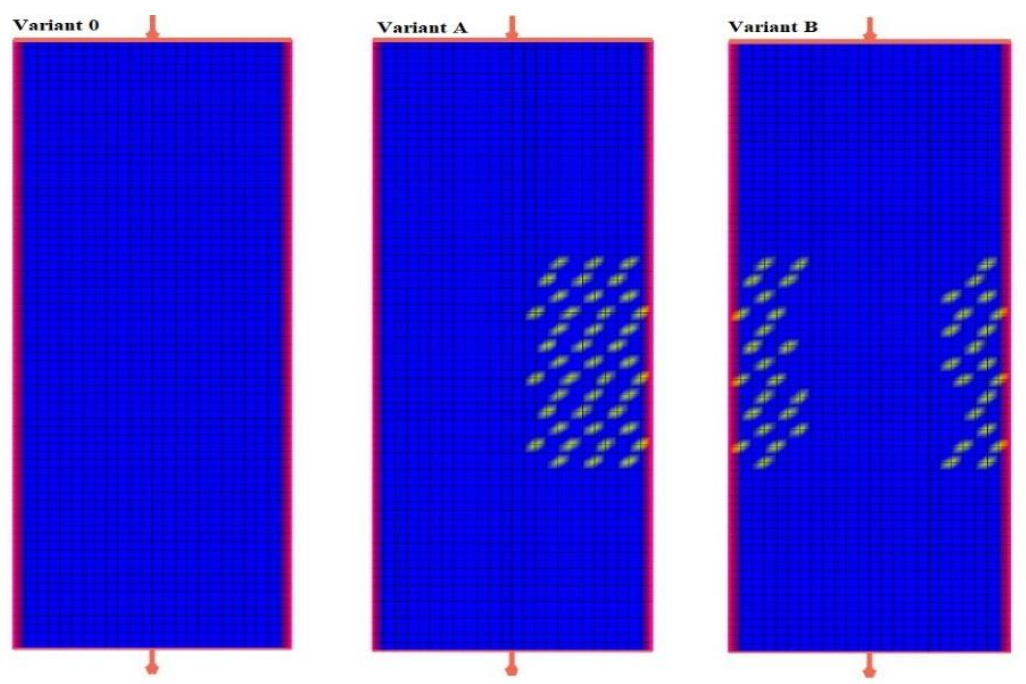

Fig. 1. Distribution of vegetation in the channel. Variant 0 No vegetation. Variant A Vegetation by the left bank. Variant B Vegetation by both banks (vegetation is symbolized with yellow points). 


\section{Methodology}

\subsection{General description of CCHE2D model}

CCHE2D (The Center for Computational Hydroscience and Engineering) was created on Mississippi University in USA. It is an integrated batch designed to perform two-dimensional simulation and analysis of water flow, debris transport and morphologic processes. It allows conducting calculations in conditions of steady flow as well as in unsteady flow [17]. Application takes into account changes in roughness of riverbed and in its geometry evoked by change of original riverbed formation and caused by transport of dragged and suspended debris during the long period of simulation.

The CCHE2D software batch includes application for creating of numerical models (CCHE2D), mesh generator (CCHE2D Mesh Generator) and graphical user interface (CCHE2D-GUI) [18]. Calculations are performed on the basis of two-dimensional mesh with use of finite element method, where computational nodes are located on apexes of quadrangles that form curvilinear net. For them, the flow parameters are directly estimated during computation phase. Values of particular parameters inside or on the sides of the element are computed with use of linear interpolation functions. The model uses vertically averaged Navier-Stokes equations, which results provide information of average vertical velocity and the ordinate of water level $[19,20]$.

\subsection{Modelling stages}

The model performance consists of following stages: 1) mesh generation, 2) estimation of boundary conditions, 3) insertion of model parameters, 4) simulation, 5) visualization and interpretation of results [20]. In this paper the mesh, which represented shape of riverbed and vegetation, was generated with use of *.mesh_xyz file, in which the points were described with basic coordinates in three dimensions: xyz. The acknowledged for this analysis spatial resolution of mesh equalled $2 \times 2 \mathrm{~cm}$. An example of mesh with included riverbed geometry is presented on Fig. 2.

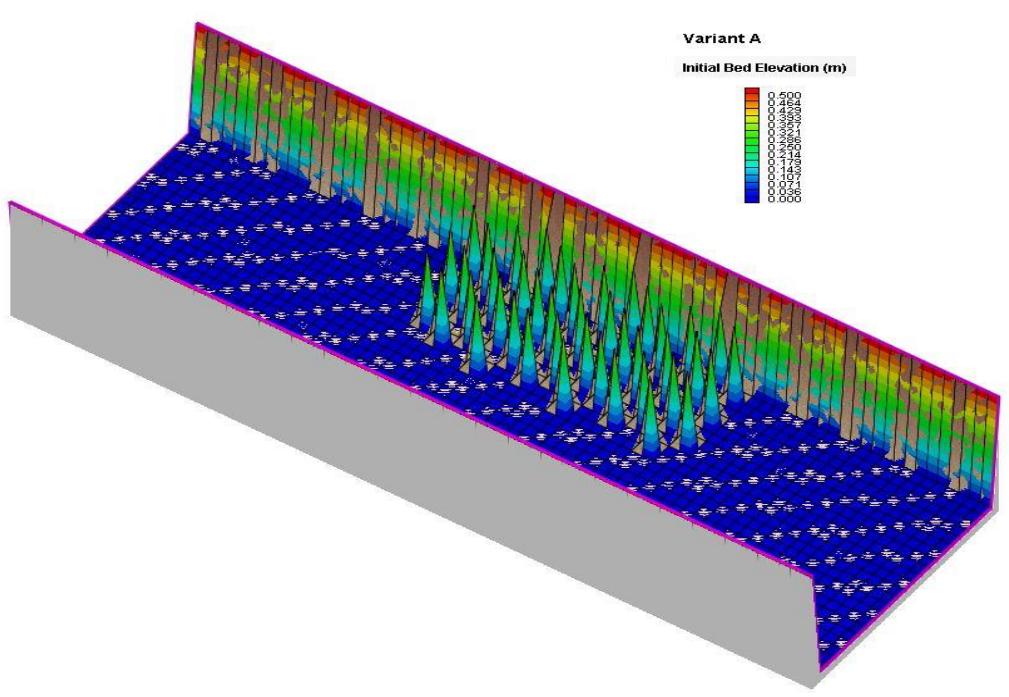

Fig. 2. 3D view of the modeled area (as example variant A). 
Upper boundary condition was defined by flows: $Q_{I}=0.05\left(\mathrm{~m}^{3} \mathrm{~s}^{-1}\right), Q_{2}=0.02\left(\mathrm{~m}^{3} \mathrm{~s}^{-1}\right)$, $Q_{3}=0.01\left(\mathrm{~m}^{3} \mathrm{~s}^{-1}\right)$. Lower boundary condition was defined as water free flow. Moreover, the initial area of water and the riverbed roughness described by Manning's roughness coefficient were defined. The simulation period equalled 240 seconds in order to enable the water stabilization process within the model. Time step was defined as 0.02 seconds. In CCHE2D model the issue of debris transport can also be analysed, but it was outside of the scope of this paper.

\section{Results and discussion}

The computations were performed for three variants of vegetation distribution and three different flow values each. The purpose of the analysis was to indicate the role of vegetation in hydraulics of channel, the evaluation of damming of water before the vegetation and the evaluation of possibility for occurrence of whirls and negative zones of increased water velocity, where erosion processes are likely to occur. The stabilized location of water table on models is presented on Fig. 3. Table 1 shows acquired maximal and mean values of water table location in the whole of area. Higher flows cause higher damming in the riverbed. In case of variants with vegetation the values of maximal level of water table are higher than in variant 0 , which proves the thesis stating vegetation impact on damming. In relation to average values for the whole of modelled area, the location of water table is not always bigger for the riverbed with vegetation (especially for flows lower than $Q_{3}=0.01\left(\mathrm{~m}^{3} \mathrm{~s}^{-1}\right)$.
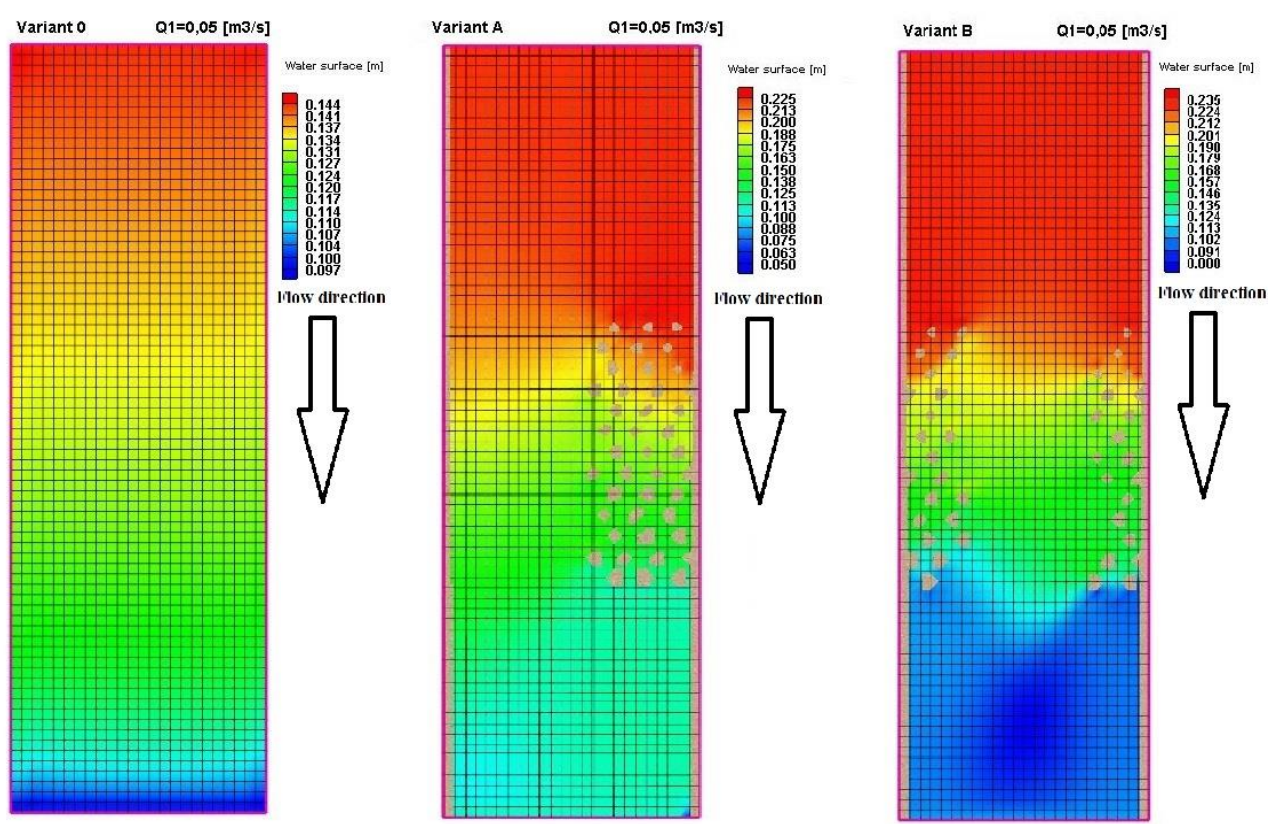

Fig. 3. Distribution of the water surface obtained in: left - variant 0 , middle - variant $\mathrm{A}$, right variant $B$. 
Table 1. Maximal and mean water surface in variants $0, \mathrm{~A}$ and $\mathrm{B}$.

\begin{tabular}{|c|c|c|c|c|}
\hline \multicolumn{2}{|c|}{$Q\left(\mathbf{m}^{\mathbf{3}} \mathbf{s}^{-\mathbf{1}}\right)$} & \multicolumn{3}{|c|}{ Water surface (m) } \\
\cline { 3 - 5 } \multicolumn{2}{|c|}{} & variant 0 & variant A & variant B \\
\hline$Q_{1}=0.05$ & Max & 0.144 & 0.225 & 0.235 \\
\cline { 2 - 5 } & Mean & 0.128 & 0.166 & 0.170 \\
\hline$Q_{2}=0.02$ & Max & 0.108 & 0.131 & 0.128 \\
\cline { 2 - 5 } & Mean & 0.105 & 0.109 & 0.101 \\
\hline$Q_{3}=0.01$ & Max & 0.094 & 0.123 & 0.107 \\
\cline { 2 - 5 } & Mean & 0.083 & 0.075 & 0.071 \\
\hline
\end{tabular}

Velocities of water flow for models are presented in Fig. 4. Table 2 shows acquired maximal and mean values of water velocity for the whole of the area. The differences between variants with and without vegetation, when it comes to mean velocities, are not big. Mean velocities equal: $v=0.65-0.76\left(\mathrm{~ms}^{-1}\right)$ for $Q_{l}, v=0.37-0.40\left(\mathrm{~ms}^{-1}\right)$ for $Q_{2}$ and $v=0.23-0.27\left(\mathrm{~ms}^{-1}\right)$ for $Q_{3}$. Much bigger are differences in case of maximal velocities. It can also be noticed in the Fig. 4, where for riverbed variants with riparian vegetation in the zone free from plants, high velocities occur, from $35 \%$ to even $115 \%$ higher than maximal velocities in riverbed with no vegetation.

Shear stress is essential in terms of stability of riverbed. It is a reflection of water velocity function. Acquired shear stress is presented on Fig. 5. Table 3 shows acquired maximal and mean values for the whole of area. Likewise in case of velocity, the maximal shear stress has a crucial impact and in case of riverbeds with riparian vegetation is even several times higher than in riverbed with no vegetation. Relating obtained values to data from literature in can be stated that in modelling conditions they are high enough to cause morphologic changes in riverbed, especially during flows of big $Q_{l}$ water [21-23].
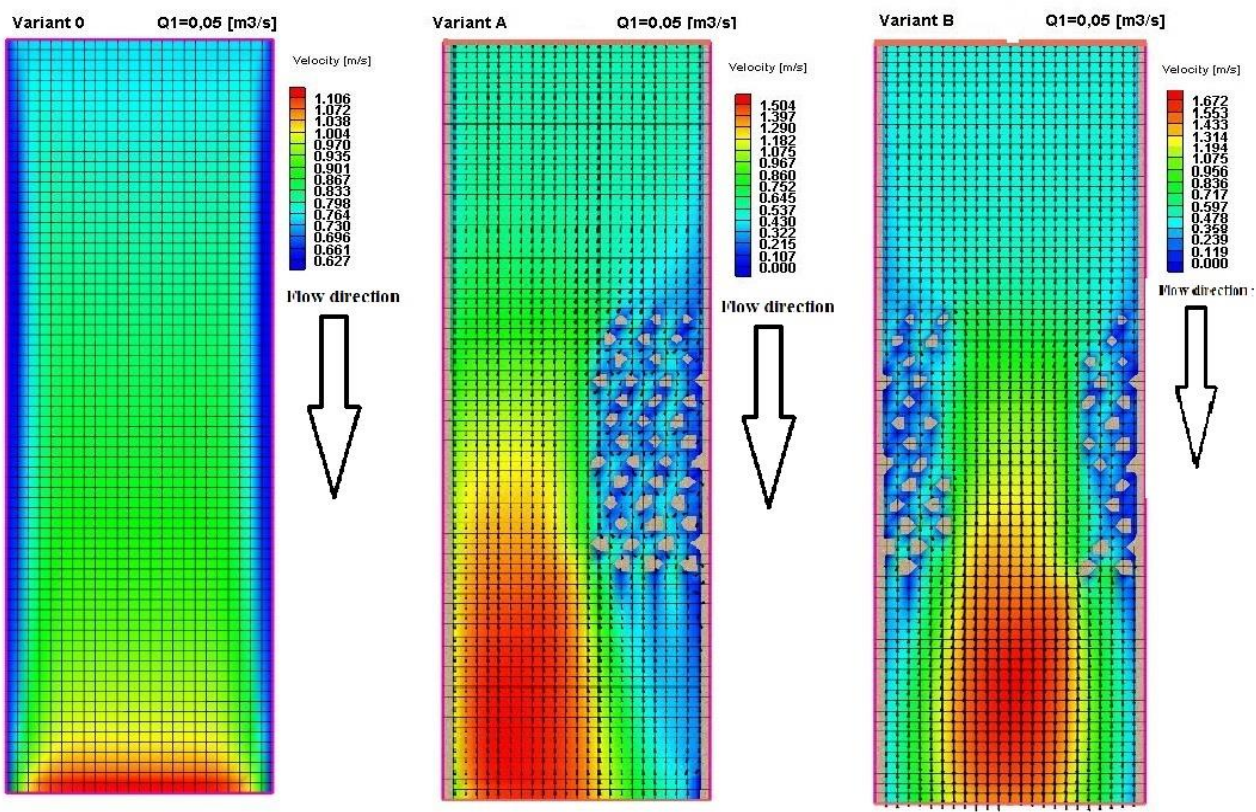

Fig. 4. Distribution of the velocity obtained in: left - variant 0 , middle - variant A, right - variant B. 
Table 2. Maximal and mean velocity in variants $0, \mathrm{~A}$ and $\mathrm{B}$.

\begin{tabular}{|c|c|c|c|c|}
\hline \multicolumn{2}{|c|}{$Q\left(\mathbf{m}^{3} \mathbf{s}^{-1}\right)$} & \multicolumn{3}{c|}{ Velocity $\left(\mathrm{ms}^{-1}\right)$} \\
\cline { 3 - 5 } \multicolumn{2}{|c|}{} & variant 0 & variant A & variant B \\
\hline $\mathrm{Q}_{1}=0.05$ & Max & 1.11 & 1.50 & 1.67 \\
\cline { 2 - 5 } & Mean & 0.76 & 0.64 & 0.65 \\
\hline $\mathrm{Q}_{2}=0.02$ & Max & 0.46 & 0.88 & 1.00 \\
\cline { 2 - 5 } & Mean & 0.37 & 0.37 & 0.40 \\
\hline $\mathrm{Q}_{3}=0.01$ & Max & 0.39 & 0.61 & 0.64 \\
\cline { 2 - 5 } & Mean & 0.23 & 0.26 & 0.27 \\
\hline
\end{tabular}
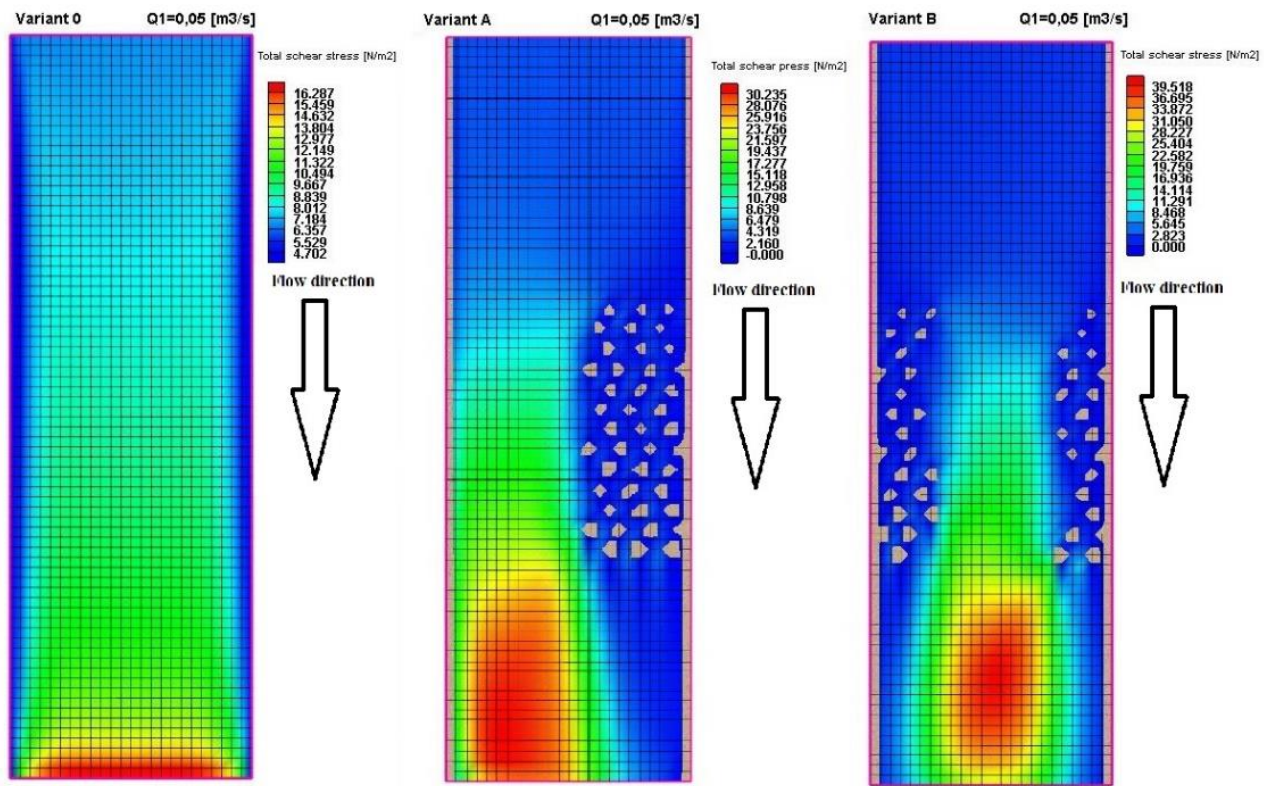

Fig. 5. Distribution of the total shear stress obtained in: left - variant 0 , middle - variant $\mathrm{A}$, right variant $\mathrm{B}$.

Table 3. Maximal and mean total shear stress in variants 0 , A and B.

\begin{tabular}{|c|c|c|c|c|}
\hline \multicolumn{2}{|c|}{$Q\left(\mathbf{m}^{3} \mathbf{s}^{-1}\right)$} & \multicolumn{3}{|c|}{ Total shear stress $\left(\mathbf{N m}^{-2}\right)$} \\
\cline { 3 - 5 } \multicolumn{2}{|c|}{} & variant 0 & variant A & variant B \\
\hline $\mathrm{Q}_{1}=0.05$ & Max & 16.3 & 30.2 & 39.5 \\
\cline { 2 - 5 } & Mean & 7.8 & 7.2 & 8.0 \\
\hline $\mathrm{Q}_{2}=0.02$ & Max & 2.8 & 10.8 & 14.6 \\
\cline { 2 - 5 } & Mean & 1.9 & 2.7 & 3.4 \\
\hline $\mathrm{Q}_{3}=0.01$ & Max & 2.1 & 5.6 & 6.4 \\
\cline { 2 - 5 } & Mean & 0.9 & 1.5 & 1.8 \\
\hline
\end{tabular}




\section{Conlusions}

The paper unequivocally proves that riparian vegetation has a significant impact on hydraulic conditions in the riverbed. Numerical analyses made it possible to define places where negative processes occur, such as the increase of velocity and shear stress. Considered variants of riparian vegetation distribution were used as preliminary research followed by research conducted with physical model in laboratory. Physical research can be used for calibration of numerical model, which was not in the scope of this paper.

In this paper the software CCHE2D was used in free version provided by National Center for Computational Hydroscience and Engineering via its official website.

\section{References}

1. T. Marjoribanks, R. Hardy, S. Lane, M. Tancock, Earth Surf. Process. Landforms, 42, 699 (2017)

2. H. Nepf, J. Hydraul. Res., 50, 262 (2012)

3. D.W Meire, J. Kondziolka, H. Nepf, Water Resour. Res., 50, 3809 (2014)

4. H. Nepf, M. Ghisalberti, Acta Geophysica, 56(3), 753 (2008)

5. ～K. Västilä, J. Järvelä, Water Resour. Res., 50(1), 229 (2014)

6. J. Green, Hydrol. Process., 19, 1245 (2005)

7. Y. Zhang, X. Lai, J. Jiang, Hydrolog. Sci. J., 61(12), 2226 (2016),

8. T. Tymiński, Infrastr. i Ekol. Ter. Wiejs. (in Polish), 7, 153 (2008)

9. J. Järvelä, Flow resistance in environmental channels: Focus on vegetation (2004)

10. Zahidi, Y. Badronnisa, M. Cope, Research in Civil and Environ. Eng., 2, 1 (2014)

11. W. Majewski, Hydraulic and Environmental Problems in Open Channel Flows in View of Water Framework Directive - 25th Intern. School of Hydraulics, 25 (2005)

12. P. Tymków, Application of photogrammetric and remote sensing methods for identification of resistance coefficients of high water flow in river valleys (2009)

13. K. Lindner, Der Strömungswiderstand von Pflanzenbeständen. Mitteilungen des Leichtweiss (in German), Doctoral thesis (1982)

14. E. Pasche, Turbulenzmechanismen in naturnahen Fließgewässern und die Möglichkeiten ihrer mathematischen Erfassung (in German), Doctoral thesis (1984)

15. T. Kałuża, T. Tymiński, Infrastr. i Ekol. Ter. Wiejs. (in Polish), 8(1), 79 (2010)

16. M. Zhao, Z. Fan, PLoS One, 12(4) (2017)

17. Y. Zhang, CCHE-GUI-Graphical user interface for the NCCHE model. User's manual - Version 3.0 (2006)

18. Z.A. Hasan, A. Ab, N.A. Zakarina, Application of 2-D Modelling for Muda River Using CCHE2D - International Conference on Managing Rivers in the 21st Century: Solution Towards Sustanable River Basins (2007)

19. Magnuszewski, M. Gutry-Korycka, Prace i Studia Geograficzne (in Polish), 43, 141 (2009)

20. M. Grobelny, J. Kubicz, T. Tymiński, Zesz. Nauk. - Inż. Ląd. Wod. Kształt. Środ., 11, 30 (2014)

21. W. Bartnik, Infrastr. i Ekol. Ter. Wiejs. (in Polish), 4(1), 143 (2006)

22. W. Parzonka, R. Kasperek, European Symposium Anti-flood Defences - Today's Problems (2012)

23. R. Duszyński, Inż. Morska i Geotech. (in Polish), 6, 341 (2007) 